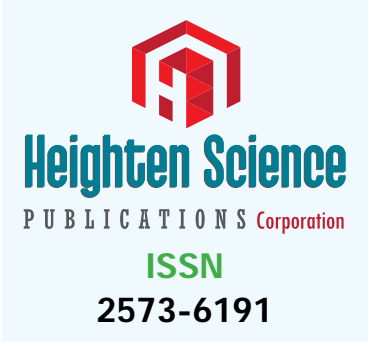

*Address for Correspondence: Mohamed Yasser Kharma, Al Farabi College of Dentistry, J eddah, KSA, Email: mykharma@hotmail.com

Submitted: 15 December 2016

Approved: 29 December 2016

Published: 30 December 2016

Copyright: @ 2016 Kharma et al. This is an open access article distributed under the Creative Commons Attribution License, which permits unrestricted use, distribution, and reproduction in any medium, provided the original work is properly cited.
Review Article

\section{Promising Future in the Detection of Oral Cancer by Using Advance Screening Technology}

\author{
Mohamed Yasser Kharma1*, Mohamed Sadek Alalwani² and \\ Manal Fouad Amer 3,4 \\ ${ }^{1}$ Professor in oral maxillofacial surgery, Aleppo University, Syria, Al farabi colleges of \\ dentistry, J eddah, KSA \\ ${ }^{2}$ Assistant professor in Immunology, Al farabi colleges of dentistry, J eddah, KSA \\ ${ }^{3}$ Assistant professor in Nursing, Al farabi colleges of dentistry and Nursing, J eddah, KSA \\ ${ }^{4}$ Department of Nursing, Cairo University, Egypt
}

Oral cancer has a tendency to be detected at late stage which is detrimental to the patients because of its high mortality and morbidity rates (survival rate $15-50 \%$ [1]). The incidence of oral cancer worldwide is approximately $3 \%$ of all malignancies, thus creating a significant worldwide health problem [2]. The most common form of oral cancer is squamous cell carcinoma (SCC), which accounts for $96 \%$ of all cancers of the oral cavity [3]. Oral squamous cell carcinoma (OSCC) and oropharyngeal and pharyngeal SCC is the sixth most common malignancy in the world today [4]. Oral cancer has a mean survival rate of five years, which is much lower than other cancers [5]. Early detection will allow oral cancer to be $90 \%$ curable and less cost effective for treatment [6].

Early detection of oral cancer is therefore important to reduce the incidence of mortality of fatal disease. Methods that are available for early detection involves being knowledgeable in oral cancer's etiology, methods for detecting and examination which require for the clinician to follow the advancement of the methods of detection. Competent, well-educated oral health care providers are needed to provide proper oral cancer screening examinations, for early oral, head, and neck cancer detection. The detection rate of OSCC screening is only $0.12 \%$ [7]. Therefore, we focused on the important of advanced screening and detecting methods for early diagnosis of oral premalignant and malignant lesions.

Tobacco use and alcohol consumption are regarded as the main risk factors for oral squamous cell carcinoma (OSCC) table 1, while human papilloma virus (HPV) infection is emerging as the leading risk factor in cancers of the oropharynx. One study of 143 patients found HPV-16 present in $16.8 \%$ of head and neck squamous cell carcinomas [8].

Visual examination may identify erythroplakia, leukoplakia, and erythroleukoplakia, which are known to have the possibility of being precancerous $[9,10]$. The earlier these cancers are detected with proper screenings, the greater chance of recovery, function, and quality of life for our patients [7]. Screening involves checking for the presence of disease in a person who is symptom-free [11]. Since many cases of early oral cancer do not present with apparent signs and symptoms, they aren't diagnosed until stages III or even IV [9]. The most common site of oral cancer and their rate of survival explain in table 2 (Source: SEER Cancer Statistics Review 1975-2004). 


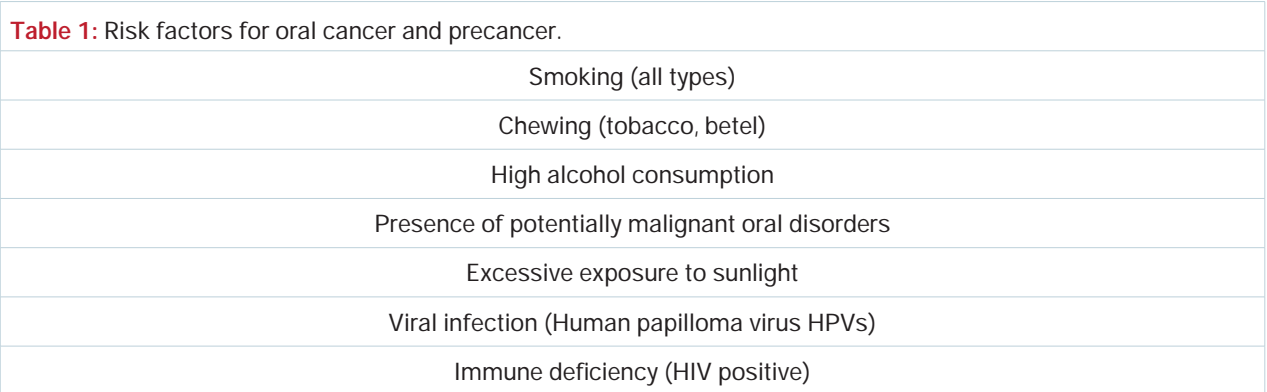

Despite numerous advances in therapy, the long-term survival of patients with OSCC associated with classic etiology, has remained modest. Several factors contribute to this poor outcome. First, OSCC is often diagnosed at an advanced stage. The 5-year survival rate of early-stage disease is $\sim 80 \%$ and in late-stage disease is only $\sim 20 \%$ [12]. Second, "field cancerization" leads to the development of multiple primary tumors with a major impact on survival. Finally primary tumors are the most common cause of treatment failure and death in patients with early-stage disease [13,14]. Therefore, comprehensive treatment plans must include improved forms of both screening and chemo-preventive strategies to improve long-term outcomes.

Cancer screening can be defined as testing asymptomatic individuals to sort out those who probably have the disease from those who probably do not. It is generally accepted that screening for OSCC and oral premalignant lesions may decrease the devastating morbidity and mortality associated with this disease. In contrast to skin cancer screening where visual examination has sensitivity and specificity rates of $93 \%$ and $98 \%$, respectively $[15,16]$.

The detection of OSCC and premalignant oral lesions by way of the conventional visual and tactile examination (CVTE) has remained problematic for several reasons. First, oral premalignant lesions and some early OSCC can be subtle in clinical appearance and can mimic inflammatory lesions. Second, it is becoming increasingly clear that some precancerous lesions are not readily identified during a conventional visual examination using incandescent light [17]. Therefore, adjunctive screening aids (devices or tests) that can improve the diagnostic accuracy of the CVTE are desperately needed. There is also considerable interest in spectroscopy (narrow field) for identifying oral premalignancy and OSCC $[18,19]$. Most other OSCC and oral premalignancy screening adjuncts are based on biomarker assessments [20-22].

Furthermore, oropharyngeal SCC is often difficult to observe during a clinical examination because it may originate in hard-to-examine locations .Early detection of a premalignant or cancerous oral lesion promises to improve the survival and the morbidity of patients suffering from these conditions.Early detection of oral cancer needs more than just understanding of the signs and symptoms of disease (Table 3: signs and symptoms). Oral cancer deaths will be reduced only if the disease is recognized earlier, avoiding delays in diagnosis, and treated sooner.

Table 2: Site of oral cancer and premalignant lesions.

$\%$ of Survival rate (5 years)

\begin{tabular}{|c|c|}
\hline Oral cavity pharynx & 29.90 \\
\hline Oral nasopharyngeal & $29.2-52.8$ \\
\hline Salivary gland & 51 \\
\hline Tongue & 54.30 \\
\hline Floor of mouth & 59.70 \\
\hline Gum & 73.90 \\
\hline Lip & 93.80 \\
\hline
\end{tabular}


Table 3: Oral cancer (Signs and Symptoms).

\begin{tabular}{|c|c|}
\hline Clinical signs & Symptoms \\
\hline Leukoplakia & Non ( asymptomatic ) \\
\hline Erythroplakia & Pain \\
\hline Erythroleukoplakia & Numbness \\
\hline Verrucous leucoplakia & Difficulty in chewing \\
\hline Ulceration & Difficulty in swallowing \\
\hline Bone resorption & Difficulty in eating \\
\hline
\end{tabular}

A significant proportion of oral squamous cell carcinomas (OSCC) develop from premalignant lesions such as leukoplakia and oral submucous fibrosis. Detection of lesions and selection of biopsy sites include vital tissue staining (with Toluidine blue and exfoliative cytology. Unfortunately, sensitivity of cytological diagnosis in a metaanalysis of 1306 cases from 14 studies showed an average of only $87.4 \%$ (ranging from 73.8 to $100 \%)$ [23].

Nowadays malignancy is considered as a process caused by the accumulation of multiple genetic alterations, which affect the cell cycle as well as normal cell differentiation. These genetic alterations, which occur during carcinogenesis, can be used as targets for detecting tumor cells in clinical samples [24-26]. Molecular analysis can identify a clonal population of cancerous cells. Mutations in the tumor suppressor gene p53 are the most frequent genetic alterations in human cancer and show a variable frequency in oral cancer [27].

The identification of tumoral markers, notably cytokeratins in smears from the oral cavity has attracted considerable interest. Cytokeratin expression profile provides useful information on cell differentiation status [28] but its potential for early diagnosis of oral cancer is limited [29] However, certain cytokeratins, such as K8 and K19 are useful as indicators of malignancy, particularly if their presence is interpreted in conjunction with other information, such as DNA profile [30]. Early detection of oral cancer needs more than just understanding of the signs and symptoms of disease. Oral cancer deaths will be reduced only if the disease is recognized and treated earlier.

\section{SCREENING PROTOCOL}

Early detection of oral cancer and related premalignancy requires an appropriate screening and diagnosis protocol. It has been recommended that all adult patients over 18 should be screened annually [31] even if medical and dental histories elicit no risk factors. Known-risk patients should be screened every six months. The strong association between HPV and oral cancer further underscores the need to screen all patients, as there is a likelihood that risk of HPV transmission will not be elicited by a medical history taken in the dental office setting. The screening protocol should include medical and dental history, unaided and aided visual examination, and palpation. All oral structures must be thoroughly examined, and any abnormalities should be recorded on a mouth map. If suspicious lesions are found during the screening procedure, the lesion must be biopsied or the patient referred to a specialist for further evaluation.

\section{Biopsy protocol}

The two basic biopsy techniques for definitive diagnosis of oral mucosal lesions are incisional biopsy and excisional biopsy. The brush biopsy (CDx) (Figure 1) is a third type of biopsy that can be used as a preliminary diagnostic tool. The brush biopsy uses a stiff brush to obtain a full-thickness sampling of epithelial cells for examination, in patients with mucosal lesions. The brush biopsy may also be useful as an intermittent preliminary diagnostic technique in patients under observation [32], while brush biopsies are practical, simple to perform, and less invasive than an incisional or excisional biopsy, they are insufficient to provide a definitive diagnosis. Incisional or excisional biopsy is the standard-of-care for definitive diagnosis. 

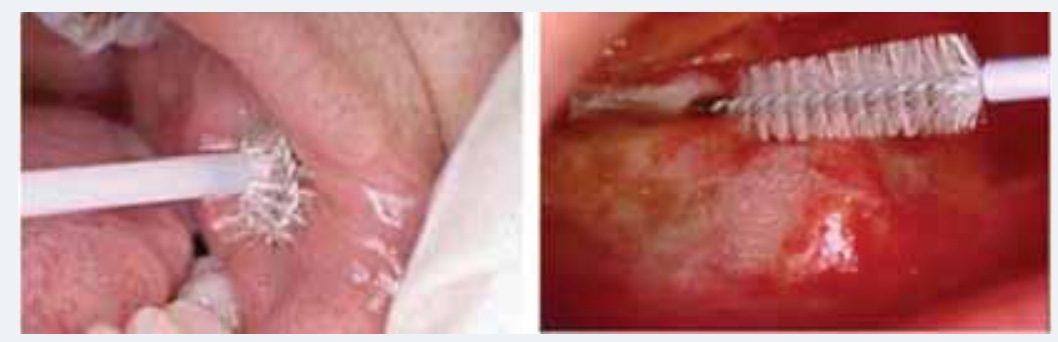

Figure 1: Brush biopsy.

Brush Biopsy is a simple, relatively inexpensive, high sensitive, risk-free method of screening for cancer and serves as an aid to the clinical examination .There are controversies related to the real value of this technique in the early detection of OSCC. The existence of false positives has been pointed out showing high sensitivity (90\%) and low specificity (3\%) [33].

Cowpe et al. [34] found that tissues undergoing malignant transformation typically show a reduction cytoplasmic area (CA), before the reduction in nuclear area (NA). Ramaesh et al. [35] used cytomorphometric techniques to assess nuclear diameter (ND) and cytoplasmic diameter (CD) in normal oral mucosa, in dysplastic lesions and in squamous cell carcinomas. They found that CD was highest in normal mucosa, lower in dysplastic lesions, and lowest in SCCs. By contrast, ND was lowest in normal mucosa, higher in dysplastic lesions, and highest in SCCs. These studies suggested that reduced nuclear size and increased cytoplasm size are useful early indicators of malignant transformation, and thus exfoliative cytology is of value for monitoring clinically suspect lesions and for early detection of malignancy [35].

Mucosal lesions that are microscopically confirmed to be benign must still be evaluated regularly for progression. In this regard, the ability to predict risk of the lesion undergoing malignant transformation could help determine the frequency of follow-up and/or earlier intervention.

\section{Toluidine Blue Staining (Figure 2)}

Vital staining of the oral mucosa with toluidine blue (as a one per cent rinse or application) has been suggested as a means of surveillance in patients at risk of developing oral cancer, and for those who have had a confirmed neoplasm in other parts of the aero digestive tract. The results and accuracy of these studies have been variable, with differing false positive and false negative rates. This could be partly due to confusion over inclusion of equivocal (pale) staining areas as positive or negative findings. Toluidine blue is most useful in secondary care for delineating the extent of lesions and for surveillance of patients at risk of recurrent disease [36,37]. It is significant for clinicians to realize that if a lesion does not stain with toluidine blue, but remains clinically suspicious for two weeks, it should still be biopsied as false negatives can occur. Toluidine blue may also aid monitoring of patients for recurrent oral cancer but is of limited use in areas with postoperative scarring where a reconstructive flap has been placed [38].

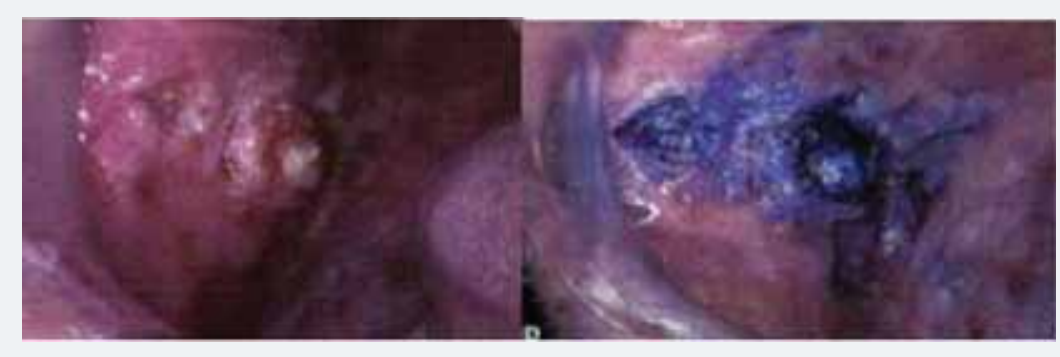

Figure 2: Toluidine blue staining. 


\section{Auto Fluorescence (VELscope $\left.{ }^{\circledR}\right)$}

The phenomenon of auto fluorescence is based on the interaction of various fluorescent tissue compounds (fluorophores) that occur naturally in the body. When excited by an appropriate light stimulus, these compounds emit visible fluorescent light in the violet to green region of the spectrum. VELscope ${ }^{\circledR}$ is a portable device comprising a light source and a viewing hand piece. The technology is based on the direct visualization of tissue fluorescence. Both keratinized and nonkeratinised squamous epithelium with a normal submucosa show a typical homogeneous, pale green fluorescence. Sharply circumscribed areas of decreased auto fluorescence might indicate areas of mucosal abnormalities that should definitely be monitored or investigated by tissue biopsy.

Microlux/ DL is a hand-held device that uses light-emitting diodes (LEDs) as the illumination source. Prior to exposing the mucosa to the light, the patient rinses for 30-60 seconds with $1 \%$ acetic acid. Upon illumination, the abnormal tissue will appear white ("aceto-white") figure 3.

\section{ViziLite and ViziLite-Plus}

ViziLite is a hand-held device that emits chemiluminescent light. The patient rinses for 30-60 seconds with $1 \%$ acetic acid and the ViziLite device is used to illuminate the oral cavity. Abnormal areas will appear white ("aceto-white") figure 4. The light increases both the brightness and the sharpness of lesions Chemiluminescence has been found to significantly assist the clinician in identifying white and erythroleukoplakia lesions [39].

Chemiluminescence examination of the oral cavity with the aid of chemiluminescent blue/white light has been suggested in several studies to improve the identification of mucosal abnormalities in comparison with normal incandescent light. Following a rinse with one per cent acetic acid for one minute under the chemiluminescence light, the normal mucosa appears blue, whereas abnormal mucosal areas reflect the light and appear more "acetowhite" with brighter, sharper margins.

\section{Salivary biomarkers}

Saliva, an aqueous biological fluid is in direct contact with the oral cancer lesion. Hence, the abnormal DNA, RNA, protein molecules released by the malignant cells

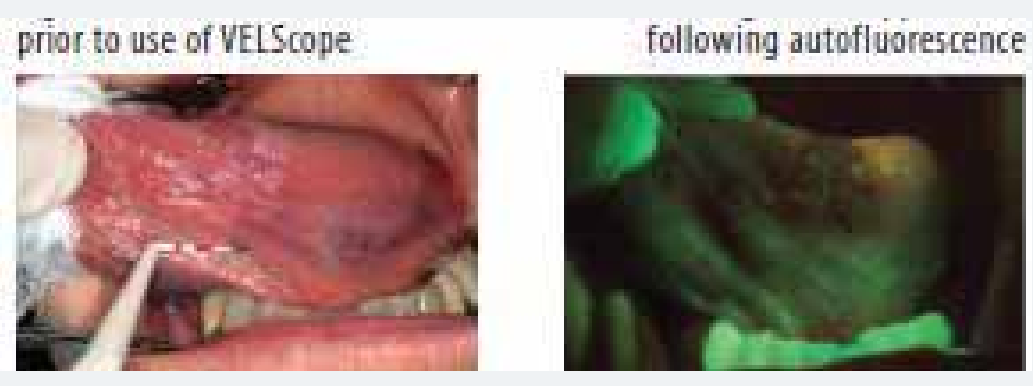

Figure 3: LEDs Illumination.

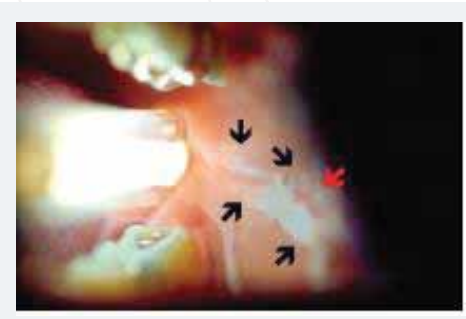

Figure 4: Aceto-white appearance with use of Vizilite. 
can be easily obtained from saliva .Saliva has been found to contain constituents that reflect the diseased or physiological state of the human body, and hence could be utilized for diagnostic purposes [40-42]. So far, more than 100 potential OSCC salivary biomarkers have been reported in the literature, based mainly on comparing the levels found in OSCC patients to the levels found in non-OSCC normal controls. Most categories of Potential salivary biomarkers for oral cancer detection are : Non-organic compound ( $\mathrm{Na}, \mathrm{Ca}, \mathrm{F}$, and $\mathrm{Mg}$ ) [43], peptid (Defensin-1) [44], proteins (IL-1, IL-6, IL-8, TNF- $\alpha$, Endothelin-1,...) [45-59], DNAs ( P53 gene codon 63,...) [60,61], mRNAs (IL-1 $\beta$, H3F3A,...) [62], Oxidative stress-related molecules (Glutathione, Peroxidase,...) [26], Glucocorticoid (Cortisol) [63], Metabolomics (Lactic acid, Valine,....) [64], Glycosylation related molecules (Sialic acid, $\alpha$-L-fucosidase) [65,66].

Despite the fact that more than 100 potential OSCC salivary biomarkers have been reported, there has been no standardization regarding the condition of the subjects from whom the saliva samples are collected (e.g., the timing in regard to prior food and drink intake, or the use of oral hygiene products). Similarly, a uniform method has not been established for how the saliva samples are collected, processed and stored prior to measurement and comparison of the biomarker levels in the groups studied.

The differences in these factors among the different studies raises the question as to whether the levels of the potential OSCC salivary biomarkers reported in any one lab could be compared to the levels of the same biomarker reported in any other lab. In fact, for the reported potential biomarkers which have been investigated by more than one study, a wide variability was found in the levels of both the diseased and the control groups among different labs. Variability in the levels of potential OSCC salivary biomarkers in both non-cancerous individuals and OSCC patients, suggest unknown confounding factors. Without standardization and validation of biomarkers, valuable research resources are being squandered, and the experts in this research field is needed to discuss this issue and find a way to establish the standards needed [67]. Salivary biomarkers represent a promising non-invasive approach for oral cancer detection, and an area of strong research interest. However, some issues (These issues include a lack of standardization for saliva sample collection, processing and storage.) need to be resolved in order to establish this approach as a reliable, highly sensitive and specific method for clinical use [67].

The interest is based on several advantages of saliva versus other body fluids, for example, serum or urine such as straightforward sample collection, sufficient quantities for analysis, and the lower costs of storage and shipping than those for serum or urine [68]. Previous studies have shown that IL-6, IL-8 are post-inflammatory cytokines, play a prominent role in immune host defense responses to infection. These chemokines are found to stimulate angiogenesis, influence tissue remodeling and take part in the regulation of cell proliferation and differentiation. They are essential mediators of cancer development and powerful activators of apoptotic and anti-apoptotic signaling cascade. Hence, IL-6 and IL-8 have been implicated in early detection of oral pre malignancies and OSCC $[69,70]$.

Screening test for oral cancer using whole saliva samples, which can be easily and noninvasively collected. A proteomic studies performed to assess changes in protein expressions of whole saliva, revealing that some proteins are either expressed or unexpressed specifically in oral squamous cell carcinoma (OSCC). Two-dimensional electrophoresis (2-DE) and peptide-mass fingerprinting (PMF) employed to identify biomarkers that specifically change expression in OSCC, the Results showed that ten protein spots were specific to the preoperative whole saliva of OSCC patients, but were absent in the whole saliva of healthy individuals and OSCC patients after surgery. Detection of enolase 1 in the saliva was shown to be significantly higher for OSCC patients than for healthy individuals. Immunohistochemical staining confirmed that appearance of enolase 1 was significantly higher in OSCC tissue than in healthy tissue [70]. 


\section{DIFFERENTIATION AND PREDICTION}

\section{I-Dysplasia and Risk Prediction}

The conventional wisdom is that the more severe a lesion's dysplasia, the more likely it is that it will undergo malignant transformation (Conversely, the less severe the dysplasia, the less likely that the lesion will undergo malignant transformation). A number of recent studies do not support this presumption. Holmstrup et al. did not find any degree of dysplasia, or site and delineation of the lesion, as a statistically significant predictor of malignancy $[71,72]$. Scully et al. have stated that while dysplasia can be predictive, that this is not always the case. They also pointed out that variability in determining the diagnosis exists between examiners as well as by the same examiner [73]. Rosin et al. studied biopsies and outcomes of patients with secondary premalignant lesions following treatment for primary oral cancer and found that the initial microscopic classification of the leukoplakia at the previously treated site did not predict a secondary oral malignancy. Forty-seven percent of leukoplakia's classified as having either no dysplasia or mild dysplasia developed into a secondary oral malignancy. Primary tumor stage, grade, and location were not significantly associated with the outcome [74]. In patients with a previous history of oral cancer, recurrences can occur at the initial site or further away and may or may not be related. Adjacent mucosa that appears clinically normal has been found to harbor geneticallyaltered cells with loss of heterozygocity [75].While a number of cancers recur due to incomplete excision of the actual lesion, it has also been suggested that premalignant cells are able to migrate to a different site out with the original lesion's area [76].

\section{II-Chromosomal abnormalities and risk prediction}

Lesions that undergo malignant transformation lose cell cycle regulation and genetic changes are evident. Recent microscopic studies have investigated loss of heterozygocity $(\mathrm{LOH})$ in tumor cells and its potential role as a risk predictor for malignant transformation. A number of chromosomal abnormalities are now known to be predictive of high risk of oral cancer. $\mathrm{LOH}$ has been found to indicate high risk of transformation or conversion to malignancy. In particular, aberrations in the $3 p, 9 p$, and $17 \mathrm{p}$ chromosomal arm sites have been implicated as high-risk predictors, although other chromosomal arm alterations also occur [77-80]. Rosin et al. examined biopsies and outcomes for patients with secondary premalignant lesions. They found that $\mathrm{LOH}$ in multiple chromosome arms, and in particular in $3 p$ and $9 p$ sites, was predictive of a secondary malignancy [81]. Aberrations in multiple arms rather than in single arms are believed to increase that risk.

\section{III-Risk prediction and treatment planning}

Given that specific chromosomal and genetic alterations have been found to be predictive of the risk of malignancy developing in a premalignant lesion, histopathology assessment of these changes will help to identify those patients most at risk in the future and enable tailored case management. Several investigators have found correlations between the degree of toluidine blue dye uptake and the presence of chromosomal alterations. Zhang et al. monitored premalignant lesions, for on average 44 months, in 100 patients with no prior oral cancer history. Toluidine blue staining was associated with a $600 \%$ increased risk of transformation and occurred in $80 \%$ of the lesions that later became malignant. The association of stain and risk factors also applied to lesions initially showing no or mild dysplasia [82]. Epstein et al. studied 32 patients with oral lesions who were biopsied following dye retention. They studied lesions with LOH on three chromosome arms (3p, 9p, and 17p). Toluidine blue positive-stained lesions demonstrated $\mathrm{LOH}$ more frequently than dye-negative lesions in $3 p$ and $9 p$, and more dye-positive cases had LOH on multiple chromosome arms, associated with an increased risk of malignancy [83]. Based on these studies, differential uptake of toluidine blue is associated with chromosomal changes and LOH rather than simply 
malignancy and/or the degree of dysplasia, and may be a useful adjunct in the future for risk prediction.

\section{CONCLUSION}

It is clear that early diagnosis of oral cancers significantly improves the patient's long-term survival. Early diagnosis also reduces morbidity and can minimize the extent of treatment required. While in other anatomic sites in the body malignancies can be radically excised, the excision of an oral cancer, depending on the site and size of the tumor, can severely compromise the patient's quality of life and in some cases may not even be possible.

The detection of suspicious lesions is increased through routine, regular screening of patients [83]. Biomarkers help in evaluating the preventive measures or therapies and the detection of the earliest stages of oral mucosal malignant transformation [84]. Early detection of suspicious lesions will result in earlier diagnosis, less aggressive treatment, and decreased need for complicated post-treatment management. The primary goal is to diagnose lesions. The secondary goal is to diagnose the malignancy before it metastasizes in order to minimize the morbidity and maximize the patient's quality of life and survival.

Ethical standards: All procedures performed in studies involving human participants were in accordance with the ethical standards of the institutional and/ or national research committee and with the 1964 Helsinki declaration and its later amendments or comparable ethical standards. Informed consent was obtained from all individual participants included in the study. Human and Animal Rights Statement This article does not contain any studies with human participants performed by any of the authors.

\section{REFERENCES}

1. Sidra Bano, David Maria Priscilla, Indira AP. Salivary Biomarkers for Oral Squamous Cell Carcinoma: An Overview. IJ SS. 2015; 1: 39-45. Ref.: https://goo.gl/nrRsv2

2. J ohnson NW, Warnakulasuriya S, Gupta PC, Dimba E, Chindia M, et al. Global oral health inequalities inincidence and outcomes for oral cancer: causes and solutions. Adv Dent Res. 2011; 23: 237-246. Ref.: https://goo.gl/95jC9Y

3. Siegel R, Naishadham D, J emal A. Cancer statistics. CA Cancer J Clin. 2012; 62: 10-29. Ref.: https://goo.gl/V5Wpln

4. J emal A, Siegel R, Ward E, Hao Y, Xu J , et al. Cancer statistics. CA Cancer J Clin. 2009; 59: 225-249. Ref.: https://goo.gl/mzqCBJ

5. Horowitz AM, Goodman HS, Yellowitz J A, Nourjah PA. The need for health promotion in oral cancer prevention and early detection. J Public Health Dent. 1996; 56: 319-330. Ref.: https://goo.gl/YrZPC2

6. Ram S, Siar $\mathrm{CH}$. Chemiluminescence as a diagnostic aid in the detection of oral cancer and potentially malignant epithelial lesions. Int J Oral and Maxillofac Surg. 2005; 34: 521-527. Ref.: https://goo.gl/sf6H1T

7. Yamamoto N, Nomura T, Takeda E, Hanaue K, Yamauchi T, et al. The present conditions and the future prospects oral cancer examination running in our department. Shikwa Gakuho. 2005; 105: 96-102.

8. Braakhuis BJ, Snijders PJ, Keune WJ, Meijer CJ , Ruijter-Schippers HJ, et al. Genetic patterns in head and neck cancers that contain or lack transcriptionally active human papillomavirus. J $\mathrm{NCl} J$ Nat Cancer Inst. 2004; 96: 998-1006. Ref.: https://goo.gl/oN0cPJ

9. Braakhuis BJ , Leemans CR, Brakenhoff RH. Expanding fields of genetically altered cells in head and neck squamous carcinogenesis. Semin Cancer Biol. 2005; 15: 113-120. Ref.: https://goo.gl/s5YpYL

10. Bigelow C, Patton L, Strauss R, Wilder R. North Carolina dental hygienist's view on oral cancer control. J ournal of Dent Hyg. 2007; 81. Ref.: https://goo.gl/P8kZeL

11. Patton LL, Epstein J B, Kerr AR. Adjunctive techniques for oral cancer examination and lesion diagnosis: A systemic review of the literature. J Am Dent Assoc. 2008; 139: 896-905. Ref.: https://goo.gl/dZnwpH

12. Ries LAG, Melbert D, Krapcho M, et al. SEER cancer statistics review, 1975-2005. Bethesda (MD): National Cancer Institute. 2008. 
13. Lippman SM, Hong WK. Second malignant tumors in head and neck squamous cell carcinoma: the overshadowing threat for patients with early-stage disease. Int J Radiat Oncol Biol Phys. 1989; 17: 691-694. Ref.: https://goo.gl/rWKOtd

14. Rennemo E, Zatterstrom U, Boysen M. Impact of second primary tumors on survival in head and neck cancer: an analysis of 2,063 cases. Laryngoscope. 2008; 118: 1350-1356. Ref.: https://goo.gl/0j1i41

15. Whited J D, Grichnik J M. The rational clinical examination. Does this patient have a mole or a melanoma? J AMA. 1998; 279: 696-701. Ref.: https://goo.gl/Gqvkxs

16. Rampen FH, Casparie-van Velsen J I, van Huystee BE, Kiemeney LA, Schouten LJ . False-negative findings in skin cancer and melanoma screening. J Am Acad Dermatol. 1995; 33: 59-63. Ref.: https://goo.gl/eeH03o

17. Thomson PJ . Field change and oral cancer: new evidence for widespread carcinogenesis? Int J Oral Maxillofac Surg. 2002; 31: 262-266. Ref.: https://goo.gl/KgN2WY

18. McGee S, Mardirossian V, Elackattu A, Mirkovic J, Pistey R, et al. Anatomy-based algorithms for detecting oral cancer using reflectance and fluorescence spectroscopy. Ann Otol Rhinol Laryngol. 2009; 118: 17-26. Ref.: https://goo.gl/IIGrss

19. Schwarz RA, Gao W, Redden Weber C, Kurachi C, Lee JJ, et al. Noninvasive evaluation of oral lesions using depth-sensitive optical spectroscopy. Cancer. 2009; 115: 1669-1679. Ref.: https://goo.gl/ZkceY2

20. Hu S, Arellano M, Boontheung P, Wang J , Zhou H, et al. Salivary proteomics oral cancer biomarker discovery. Clin Cancer Res. 2008; 14: 6246-6252. Ref.: https://goo.gl/e79blr

21. Park NJ, Zhou H, Elashoff D, Henson BS, Kastratovic DA, et al. Salivary microRNA: discovery, characterization, and clinical utility for oral cancer detection. Clin Cancer Res. 2009; 15: 5473-5477. Ref.: https://goo.gl/AUtY1S

22. Weigum SE, Floriano PN, Redding SW, Yeh CK, Westbrook SD, et al. Nano-bio-chip sensor platform for examination of oral exfoliative cytology. Cancer Prev Res. 2010; 3: 518-528. Ref.: https://goo.gl/C2J wpJ

23. Carvalho AL,J eronimo C, Kim MM, Henrique R,Zhang Z, et al. Evaluation of promoter hypermethylation detection in body fluids as a screening/diagnosis tool for head and neck squamous cell carcinoma. Clin Cancer Res. 2008; 14: 97-107. Ref.: https://goo.gl/ljzLz0

24. Kaugars GE, Silverman S J r, Ray AK, Page DG, Abbey LM, et al. The use of exfoliative cytology for the early diagnosis of oral cancers: is there a role for it in education and private practice? J Cancer Educ. 1998; 13: 85-89. Ref.: https://goo.gl/KIW7Q7

25. Ogden GR, Cowpe J G, Green MW. Detection of field change in oral cancer using oral exfoliative cytologic study. Cancer. 1991; 68: 1611-1615. Ref.: https://goo.gl/j5bLZG

26. Spafford MF, Koch WM, Reed AL, Califano J A, Xu LH, et al. Detection of head and neck squamous cell carcinoma among exfoliated oral mucosal cells by microsatellite analysis. Clin Cancer Res. 2001; 7: 607-612. Ref.: https://goo.gl/15Sv33

27. Boyle J O, Mao L, Brennan J A, Koch WM, Eisele DW, et al. Gene mutations in saliva as molecular markers for head and neck squamous cell carcinomas. Am J Surg. 1994; 168: 429-432. Ref.: https://goo.gl/CMPyv5

28. Williams HK. Molecular pathogenesis of oral squamous carcinoma. Mol Pathol. 2000; 53: 165-172. Ref.: https://goo.gl/EJ ebgx

29. Remmerbach TW, Weidenbach H, Müller C, Hemprich A, Pomjanski N, et al. Diagnostic value of nucleolar organizer regions (AgNORs) in brush biopsies of suspicious lesions of the oral cavity. Anal Cell Pathol. 2003; 25: 139-146. Ref.: https://goo.gl/dVQUu2

30. Ogden GR, Chisholm DM, Adi M, Lane EB. Cytokeratin expression in oral cancer and its relationship to tumour differentiation. J Oral Pathol Me. 1993; 22: 82-86. Ref.: https://goo.gl/tA7AUK

31. Ogden GR, McQueen S, Chisholm DM, Lane EB. Keratin profiles of normal and malignant oral mucosa using exfoliative cytology. J Clin Pathol. 1993; 46: 352-356. Ref.: https://goo.gl/UqkhzX

32. Ogden GR, Cowpe J G, Chisholm DM, Lane EB. DNA and keratin analysis of oral exfoliative cytology in the detection of oral cancer. Eur J Cancer B Oral Oncol. 1994; 30: 405-408. Ref.: https://goo.gl/iEpBfK

33. J oseph BK. Oral cancer: prevention and detection. Med Princ Pract. 2002; 11: 32-35. Ref.: https://goo.gl/Q2xUcH

34. Kosicki DM, Riva C, Pajarola GF, Burkhardt A, Gratz KW. OralCDx brush biopsy-a tool for early diagnosis of oral squamous cell carcinoma. Schweiz Monatsschr Zahnmed. 2007; 117: 222-227. Ref.: https://goo.gl/mpPc7Z

35. Rick GM. Oral brush biopsy: the problem of false positives. Oral Surg Oral Med Oral Pathol Oral Radiol Endod. 2003; 96: 252. Ref.: https://goo.gl/UZrHP6 
36. Cowpe J G, Longmore RB, Green MW. Quantitative exfoliative cytology of abnormal oral mucosal smears. J R Soc Med. 1988; 81: 509-513. Ref.: https://goo.gl/vX50Q0

37. Ramaesh T, Mendis BR, Ratnatunga N, Thattil RO. Cytomorphotometric analysis of squames obtained from normal oral mucosa and lesions of oral leukoplakia and squamous cell carcinoma. J Oral Pathol Med. 1998; 27: 83-86. Ref.: https://goo.gl/go39zo

38. Zhang L, Williams M, Poh CF, Laronde D, Epstein J B, et al. Toluidine blue staining identifi es highrisk primary oral premalignant lesions with poor outcome. Cancer Res. 2005; 65: 8017-8021. Ref.: https://goo.gl/mH3b3h

39. Gandolfo S, Pentenero M, Broccoletti R, Pagano M, Carrozzo M, et al. Toluidine blue uptake in potentially malignant oral lesions in vivo: clinical and histological assessment. Oral Oncol. 2006; 42: 89-95. Ref.: https://goo.gl/wFUOGy

40. Pabiszczak M, Wierzbicka M, Wasniewska E, Szyfter W. Toluidine blue in monitoring of recurrences and second primary tumors in patients treated for oral cavity and pharynx cancer. Otolaryngol Pol. 2006; 60: 691-695. Ref.: https://goo.gl/QI70qr

41. Epstein J B, Gorsky M, Lonky S, Silverman S J r, Epstein J D, et al. The efficacy of oral lumenoscopy (ViziLite) in visualizing oral mucosal lesions. Spec Care Dentist. 2006; 26: 171174. Ref.: https://goo.gl/f5AsqX

42. Wong DT. Salivary diagnostics for oral cancer. J Calif Dent Assoc. 2006; 34: 303-308. Ref.: https://goo.gl/j5h32N

43. Wong DT. Salivary diagnostics powered by nanotechnologies, proteomics and genomics. J Am Dent Assoc. 2006; 137: 313-321. Ref.: https://goo.gl/aG5zql

44. Castagnola M, Picciotti PM, Messana I, Fanali C, Fiorita Am, et al. Potential applications of human saliva as diagnostic fluid. Acta Otorhinolaryngol Ital. 2011; 31: 347-357. Ref.: https://goo.gl/e8EHmy

45. Shpitzer T, Bahar G, Feinmesser R, Nagler RM. A comprehensive salivary analysis for oral cancer diagnosis. J Cancer Res Clin Oncol. 2007; 133: 613-617. Ref.: https://goo.gl/ouWIZY

46. Mizukawa N, Sugiyama K, Fukunaga J , Ueno T, Mishima K, et al. Defensin-1, a peptide detected in the saliva of oral squamous cell carcinoma patients. Anticancer Res. 1998; 18: 4645-4649. Ref.: https://goo.gl/TJ TRn7

47. Chen YC, Li TY, Tsai MF. Analysis of the saliva from patients with oral cancer by matrix-assisted laser desorption/ionization time-of-flight mass spectrometry. Rapid Commun Mass Spectrom. 2002; 16: 364-369. Ref.: https://goo.gl/Om9gsl

48. Pickering V, J ordan RC, Schmidt BL. Elevated salivary endothelin levels in oral cancer patients-a pilot study. Oral Oncol. 2007; 43: 37-41. Ref.: https://goo.gl/Zoqclk

49. St J ohn MA, Li Y, Zhou X, Denny P, Ho CM, et al. Interleukin 6 and interleukin 8 as potential biomarkers for oral cavity and oropharyngeal squamous cell carcinoma. Arch Otolaryngol Head Neck Surg. 2004; 130: 929-935. Ref.: https://goo.gl/7eWpHq

50. Rhodus NL, Ho V, Miller CS, Myers S, Ondrey F. NF-kappaB dependent cytokine levels in saliva of patients with oral preneoplastic lesions and oral squamous cell carcinoma. Cancer Detect Prev. 2005; 29: 42-45. Ref.: https://goo.gl/kxWFGo

51. Nagler R, Bahar G, Shpitzer T, Feinmesser R. Concomitant analysis of salivary tumor markers-a new diagnostic tool for oral cancer. Clin Cancer Res. 2006; 12: 3979-3984. Ref.: https://goo.gl/zh6pu

52. Vucicevic Boras V, Cikes N, Lukac J , Virag M, Cekic-Arambasin A. Salivary and serum interleukin 6 and basic fibroblast growth factor levels in patients with oral squamous cell carcinoma. Minerva Stomatol. 2005; 54: 569-573. Ref.: https://goo.gl/Wyug6c

53. Hu S, Arellano M, Boontheung $P$, Wang J , Zhou H. Salivary proteomics for oral cancer biomarker discovery. Clin Cancer Res. 2008; 14: 6246-6252. Ref.: https://goo.gl/Qv3QHp

54. Katakura A, Kamiyama I, Takano N, Shibahara T, Muramatsu T. Comparison of salivary cytokine levels in oral cancer patients and healthy subjects. Bull Tokyo Dent Coll. 2007; 48: 199-203. Ref.: https://goo.gl/6l85ZE

55. J ou YJ , Lin CD, Lai CH, Chen CH, Kao J Y. Proteomic identification of salivary transferrin as a biomarker for early detection of oral cancer. Anal Chim Acta. 2010; 681: 41-48. Ref.: https://goo.gl/Ms4P1K

56. Franzmann EJ, Reategui EP, Pedroso F, Pernas FG, Karakullukcu BM, et al. Soluble CD44 is a potential marker for the early detection of head and neck cancer. Cancer Epidemiol Biomarkers Prev. 2007; 16: 1348-1355. Ref.: https://goo.gl/i5u9Zm

57. Shpitzer T, Hamzany $Y$, Bahar G, Feinmesser R, Savulescu D. Salivary analysis of oral cancer biomarkers. Br J Cancer. 2009; 101: 1194-1198. Ref.: https://goo.gl/P2Vuxv

58. He H, Chen G, Zhou L, Liu Y. A joint detection of CEA and CA-50 levels in saliva and serum of patients with tumors in oral region and salivary gland. J Cancer Res Clin Oncol. 2009; 135: 13151321. Ref.: https://goo.gl/uPzchr 
59. Shpitzer T, Bahar G, Feinmesser R, Nagler RM. A comprehensive salivary analysis for oral cancer diagnosis. J Cancer Res Clin Oncol. 2007; 133: 613-617. Ref.: https://goo.gl/okwilw

60. J essie K, J ayapalan J J , Ong KC, Abdul Rahim ZH, Zain RM, et al. Aberrant proteins in the saliva of patients with oral squamous cell carcinoma. Electrophoresis. 2013; 34: 2495-2502. Ref.: https://goo.gl/rX73Kz

61. J ou YJ , Lin CD, Lai CH, Tang CH, Huang SH, et al. Salivary zinc finger protein 510 peptide as a novel biomarker for detection of oral squamous cell carcinoma in early stages. Clin Chim Acta. 2011; 412 1357-1365. Ref.: https://goo.gl/uYCchU

62. El-Naggar AK, Mao L, Staerkel G, Coombes MM, Tucker SL, et al. Genetic heterogeneity in saliva from patients with oral squamous carcinomas: implications in molecular diagnosis and screening. J Mol Diagn. 2001; 3: 164-170. Ref.: https://goo.gl/qliZRP

63. Carvalho AL, Henrique R, J eronimo C, Nayak CS, Reddy AN, et al. Detection of promoter hypermethylation in salivary rinses as a biomarker for head and neck squamous cell carcinoma surveillance. Clin Cancer Res. 2011; 17: 4782-4789. Ref.: https://goo.gl/xP3tO1

64. Li Y, St J ohn MA, Zhou X, Kim Y, Sinha U, et al. Salivary transcriptome diagnostics for oral cancer detection. Clin Cancer Res. 2004; 10: 8442-8450. Ref.: https://goo.gl/CmhfkF

65. Bernabe DG, Tamae AC, Miyahara GI, Sundefeld ML, Oliveira SP, et al. Increased plasma and salivary cortisol levels in patients with oral cancer and their association with clinical stage. J Clin Pathol. 2012; 65: 934-939. Ref.: https://goo.gl/yprN95

66. Sugimoto M, Wong DT, Hirayama A, Soga T, Tomita M. Capillary electrophoresis mass spectrometrybased saliva metabolomics identified oral, breast and pancreatic cancer-specific profiles. Metabolomics. 2010; 6: 78-95. Ref.: https://goo.gl/fXhSOF

67. Vajaria BN, Patel KR, Begum R, Shah FD, Patel J B, et al. Evaluation of serum and salivary total sialic acid and alpha-l-fucosidase in patients with oral precancerous conditions and oral cancer. Oral Surg Oral Med Oral Pathol Oral Radiol. 2013; 115: 764-771. Ref.: https://goo.gl/z8hVsh

68. Wei J , Xie G, Zhou Z, Shi P, Qiu Y, et al. Salivary metabolite signatures of oral cancer and leukoplakia. Int J Cancer. 2011; 129: 2207-2217. Ref.: https://goo.gl/HaBuuD

69. Banks RE, Dunn MJ , Hochstrasser DF, Sanchez J C, Blackstock W, et al. Proteomics: new perspectives, new biomedical opportunities. Lancet. 2000; 18: 1749-1756. Ref.: https://goo.gl/zFMrVy

70. Li Y, St J ohn MAR, Zhou X, Kim Y, Sinha U, et al. Salivary trans-criptome diagnostics for oral cancer detection. Clin Cancer Res. 2004; 10: 8442-8450. Ref.: https://goo.gl/pV0Eqp

71. Li Y, Zhou X, St] ohn MAR, Wong DT. RNA Profiling of cell-free saliva usingmicroarray technology. J Dent Res. 2004; 83: 199-203. Ref.: https://goo.gl/1V6QNr

72. Holmstrup $P$, Vedtofte $P$, Reibel $\mathrm{J}$, Stoltze K. Long-term treatment outcome of oral premalignant lesions. Oral Oncol. 2006; 42: 461-474. Ref.: https://goo.gl/kQgg98

73. Holmstrup $P$, Vedtofte $P$, Reibel J , Stoltze K. Oral premalignant lesions: is a biopsy reliable? J Oral Pathol Med. 2007; 36: 262-266. Ref.: https://goo.gl/m3IQCE

74. Scully C, Sudbø J Speight PM. Progress in determining the malignant potential of oral lesions. J Oral Pathol Med. 2003; 32: 251-256. Ref.: https://goo.gl/AqRBzc

75. Rosin MP, Lam WL, Poh C, Le ND, Li RJ, et al. 3p14 and 9p21 loss is a simple tool for predicting second oral malignancy at previously treated oral cancer sites. Cancer Res. 2002; 62: 6447-6450. Ref.: https://goo.gl/tFGHd2

76. Tabor MP, Brakenhoff RH, van Houten VMM, Kummer J A, Snel MHJ , et al. Persistence of genetically altered fields in head and neck cancer patients: Biological and clinical implications. Clin Cancer Res. 2001; 7: 1523-1532. Ref.: https://goo.gl/gsXiAT

77. Braakhuis BJ M, Tabor MP, Kummer J A, Leemans CR, Brakenhoff RH. A genetic explanation of Slaughter's concept of field cancerization: evidence and clinical implications. Cancer Research. 2003; 63: 1727-1730. Ref.: https://goo.gl/W15g1R

78. Partridge M, Pateromichelakis S, Phillips E, Emilion GG, Ahern RP, et al. A case-control study confirms that microsatellite assay can identify patients at risk of developing oral squamous cell carcinoma within a field of cancerization. Cancer Res. 2000; 60: 3893-3898. Ref.: https://goo.gl/nma83F

79. Mao L, Lee J S, Fan YH, Ro J Y, Batsakis J G, et al. Frequent microsatellite alterations at chromosomes 9 p21 and 3p14 in oral premalignant lesions and their value in cancer risk assessment. Nat. Med. 1996; 2: 682-685. Ref.: https://goo.gl/S6TPUV

80. Guo Z, Yamaguchi K, Sanchez-Cespedes M, Westra WH, Koch WM. Allelic losses in OraTest-directed biopsies of patients with prior upper aerodigestive tract malignancy. Clin Cancer Res. 2001; 7: 1963-1968. Ref.: https://goo.gl/fFldRF

81. Nawroz $\mathrm{H}$, van der Riet $\mathrm{P}$, Hruban $\mathrm{RH}$, Koch W, Ruppert J M. Allelotype of head and neck squamous cell carcinoma. Cancer Res. 1994; 54: 1152-1155. Ref.: https://goo.gl/DxNeyV 
82. Zhang L, Williams M, Poh CF, Laronde D, Epstein J B, et al. Toluidine blue staining identifi es highrisk primary oral premalignant lesions with poor outcome. Cancer Res. 2005; 65: 8017-8021. Ref.: https://goo.gl/ffvKch

83. Epstein J B, Zhang L, Poh C, Nakamura H, Berean K, et al. Increased allelic loss in toluidine bluepositive oral premalignant lesions. Oral Surg Oral Med Oral Pathol Oral Radiol Endod. 2003; 95: 45-50. Ref.: https://goo.gl/kNxN1y 